\title{
Factors associated with multimorbidity in the elderly: an integrative literature review
}

\author{
Laércio Almeida de Melo' ${ }^{\text {ID }}$ \\ Luciana de Castro Braga² $\mathbb{I D}$ \\ Fabíola Pessôa Pereira Leite ${ }^{2} \mathbb{D}$ \\ Breno Fortes Bittar ${ }^{2}$ ID \\ Jéssica Mayara de Figueirêdo Oséas' (ID \\ Kenio Costa de Lima' $\mathbb{D}$
}

\section{Abstract}

Objective: The objective of the present study was to identify factors associated with multimorbidity in the elderly through an integrative literature review. Method: The "Cochrane Library", "MEDLINE", "Web of Science", "Scopus" and "LILACS” databases were used, as well as the "SciELO" virtual library and the electronic search engine "Google Academic". The following search terms were applied: "multimorbidity"; "multimorbidity"; "comorbidity; "multiple diseases"; "elderly"; "major adults”, "older people”, "older persons", "aged", "associated factors", "correlated factors", "socioeconomic factors" and "demographic factors." The inclusion criterion was that the object of the study was the elderly population with multimorbidity. Studies in which multimorbidity was not the dependent variable were excluded. Results: a total of seven articles were included in this review. A prevalence of multimorbidity in the elderly ranging from $30.7 \%$ to $57 \%$ was found. The associated factors were smoking, alcohol consumption, lived in rural areas, low levels of schooling, the female gender, older elderly persons and not living with children. In the majority of articles a low level of family income was also associated with multimorbidity. Conclusion: The results suggest that multimorbidity in the elderly is a common condition and that it is influenced by socioeconomic and demographic factors, lifestyle and family structure.

\footnotetext{
Universidade Federal do Rio Grande do Norte, Departamento de Odontologia. Natal, Rio Grande do Norte, Brasil.

2 Universidade Federal de Juiz de Fora, Departamento de Odontologia. Juiz de Fora, Minas Gerais, Brasil.

Keywords: Elderly. Multimorbidity. Chronic Disease. 


\section{INTRODUCTION}

In modern times, it has become increasingly important to take care of one's health, since reducing vulnerability to illness strengthens protection against disability, chronic suffering and premature death. In the elderly, specifically, identifying and seeking to reduce the factors that lead to illness is crucial, as this segment of the population is characterized by vulnerability and the reduction of functional capacity in their stage of life'.

Although infectious diseases remain and are still important, there is a significant increase in chronic non-communicable diseases ${ }^{2}$. Such conditions are capable of generating disabilities and a high level of limitation in activities of daily living and leisure, as well as placing great pressure on the health services ${ }^{2}$.

With the increase in life expectancy and the occurrence of chronic diseases, multimorbidity, which corresponds to the occurrence of different health problems in the same individual, is a frequent problem, especially in the elderly population ${ }^{3}$. Although this concept is well-established in literature, the definition of multimorbidity in relation to the number of chronic conditions considered varies greatly, with some authors considering the condition to be the presence of at least two chronic diseases and others the presence of at least three ${ }^{4}$.

Considering its prevalence, severity and impact on quality of life, multimorbidity is a current public health problem ${ }^{5}$. The global prevalence of different health problems in the elderly is high, with a percentage of over $50 \%$ and, according to studies, there is a tendency for this number to increase ${ }^{6-9}$. The consequences of multimorbidity include greater risks of death and functional decline, as well as an impact on the reduction of life expectancy ${ }^{10,11}$. Although it can be controlled, adequate management of multimorbidity is a challenge for global health systems and services due to the high cost and complexity of treatment ${ }^{6,12}$.

The identification of associated factors related to the prevalence of multimorbidities, through current data, is paramount for the definition of health policies aimed at the prevention of disease, and to support the formulation of public policies in the areas of health promotion, vigilance and care ${ }^{13}$.

The present study therefore aimed, through an integrative literature review, to identify factors associated with multimorbidity in the elderly.

\section{METHOD}

An integrative review of cross-sectional and longitudinal studies published in literature was carried out to identify factors associated with multimorbidity among the elderly. The inclusion criteria consisted of cross-sectional or longitudinal studies with the object of study the elderly population (individuals over 60 years old) with multimorbidity.

The review included studies that considered multimorbidity to be the accumulation of two or more chronic diseases, and those that considered it to be the accumulation of three or more. In addition, chronic diseases were considered to be those proposed in 1957 by the Cambridge Commission on Chronic Diseases (United States), which include all conditions containing at least one of the following characteristics: permanence, presence of residual disability, non-reversible pathological alteration to the body system, need for special training of patient for rehabilitation and provision of a long period of supervision, observation and care ${ }^{14}$.

There was no restriction of year of publication and language. We excluded studies evaluating multimorbidity and its associated factors in children, adolescents and adults. In addition, we also excluded studies in which multimorbidity was not considered as the dependent variable.

The electronic search strategies were conducted by three researchers, independently, during the period from May 2018 to July 2018, in the Cochrane Library, MEDLINE, Web of Science, Scopus and LILACS databases. The "SciELO" virtual library and the "Google Scholar" electronic search engine were also used. The following descriptors and/or keywords were used: "multimorbidity"; "multi-morbidity"; "comorbidity"; "multiple diseases"; "elderly"; "major adults", "olderpeople", "older persons", "aged", "associated factors", 
"correlated factors", "socioeconomic factors" and "demographic factors". In addition to surveying the aforementioned databases, manual searches were also carried out using the references of articles on the subject. The search strategies developed for each database are described in Chart 1.

After the database and manual searches, the titles and abstracts were organized into a standard form. Using the same selection criteria, the three main researchers then chose the studies with the potential to be read in their entirety and included in the review.

Data from the studies read in full and included in the review were recorded in a data extraction sheet by the three authors who independently and jointly recorded data relating to the survey (sample, country where the study was conducted and factors associated with multimorbidities), methodological characteristics (type of study) and outcomes.

In the presence of disagreements, the authors consulted a fourth author and, through a consensus, reached a common decision. For the evaluation of the quality of the selected studies, the method proposed by Loney ${ }^{15}$ was used, which critically evaluates studies on the prevalence or incidence of health problems. This critical evaluation is based on eight items: appropriate study design, sampling process design, adequate sample size, use of validated methods, unbiased measurement of data, sample loss of less than $30 \%$, confidence intervals present in the sample, determination of prevalence or incidence and detailed description of study subjects. Each of these items, when appropriate, scores 1 point, and in total each study can vary in score from 0 to 8 points.

\section{RESULTS}

The electronic search strategy used resulted in 356 titles and abstracts. Of these, 25 were selected from the inclusion and exclusion criteria and read in their entirety. The manual search, made from the references of the articles read in full, resulted in the retrieval of one article. In the end, seven studies were selected for inclusion in the review (Figure 1).

Chart 1. Search strategies used in databases, virtual library and electronic search engine.

\begin{tabular}{|c|c|}
\hline BASE & STRATEGY \\
\hline Pubmed, Medline & $\begin{array}{l}\text { ("multimorbidity" OR "multi-morbidity" OR "multiple diseases" OR “comorbidity") AND ("elderly" OR } \\
\text { "major adults" OR "older people" OR "older persons" OR "aged") AND ("associated factors" OR "correlated } \\
\text { factors" OR "socioeconomic factors" OR "demographic factors") }\end{array}$ \\
\hline Web of Science & $\begin{array}{l}\text { TS=("multimorbidity" OR "multi-morbidity" OR "multiple diseases" OR "comorbidity") AND } \\
\text { TS=("elderly" OR "major adults" OR "older people" OR "older persons" OR "aged") AND TS=("associated } \\
\text { factors" OR "correlated factors" OR "socioeconomic factors" OR "demographic factors") }\end{array}$ \\
\hline Scopus & $\begin{array}{l}\text { TITLE-ABS-KEY("multimorbidity" OR "multi-morbidity" OR "multiple diseases" OR “comorbidity") } \\
\text { AND TITLE-ABS-KEY("elderly" OR "major adults" OR "olderpeople" OR "olderpersons" OR } \\
\text { "aged") AND TITLE-ABS-KEY("associated factors" OR "correlated factors" OR "socioeconomic factors" } \\
\text { OR "demographic factors") }\end{array}$ \\
\hline Cochrane & $\begin{array}{l}\text { "multimorbidity" OR "multi-morbidity" OR "multiple diseases" OR "comorbidity" and "elderly" OR "major } \\
\text { adults" OR "older people" OR "olderpersons" OR "aged" and "associated factors" OR "correlated factors" OR } \\
\text { "socioeconomic factors" OR "demographic factors" }\end{array}$ \\
\hline Lilacs & $\begin{array}{l}\text { "multimorbidity" OR "multi-morbidity" OR "multiple diseases" OR "comorbidity" [Words] and "elderly" } \\
\text { OR "major adults" OR "older people" OR "older persons" OR "aged" [Words] and "associated factors" OR } \\
\text { "correlated factors" OR "socioeconomic factors" OR "demographic factors" [Words] }\end{array}$ \\
\hline Scielo & $\begin{array}{l}\text { (“multimorbidity" OR "multi-morbidity" OR "multiple diseases" OR "comorbidity") AND ("elderly" } \\
\text { OR "major adults" OR "older people" OR "olderpersons" OR "aged") AND ("associated factors" OR } \\
\text { "correlated factors" OR "socioeconomic factors" OR "demographic factors") }\end{array}$ \\
\hline Google Scholar & $\begin{array}{l}\text { "multimorbidity" + "multi-morbidity" + "multiple diseases" + "comorbidity" + "elderly" + "major adults" + } \\
\text { "olderpeople" + "older persons" + "aged" + "associated factors" + "correlated factors" + "socioeconomic factors" } \\
\text { + "demographic factors" }\end{array}$ \\
\hline
\end{tabular}




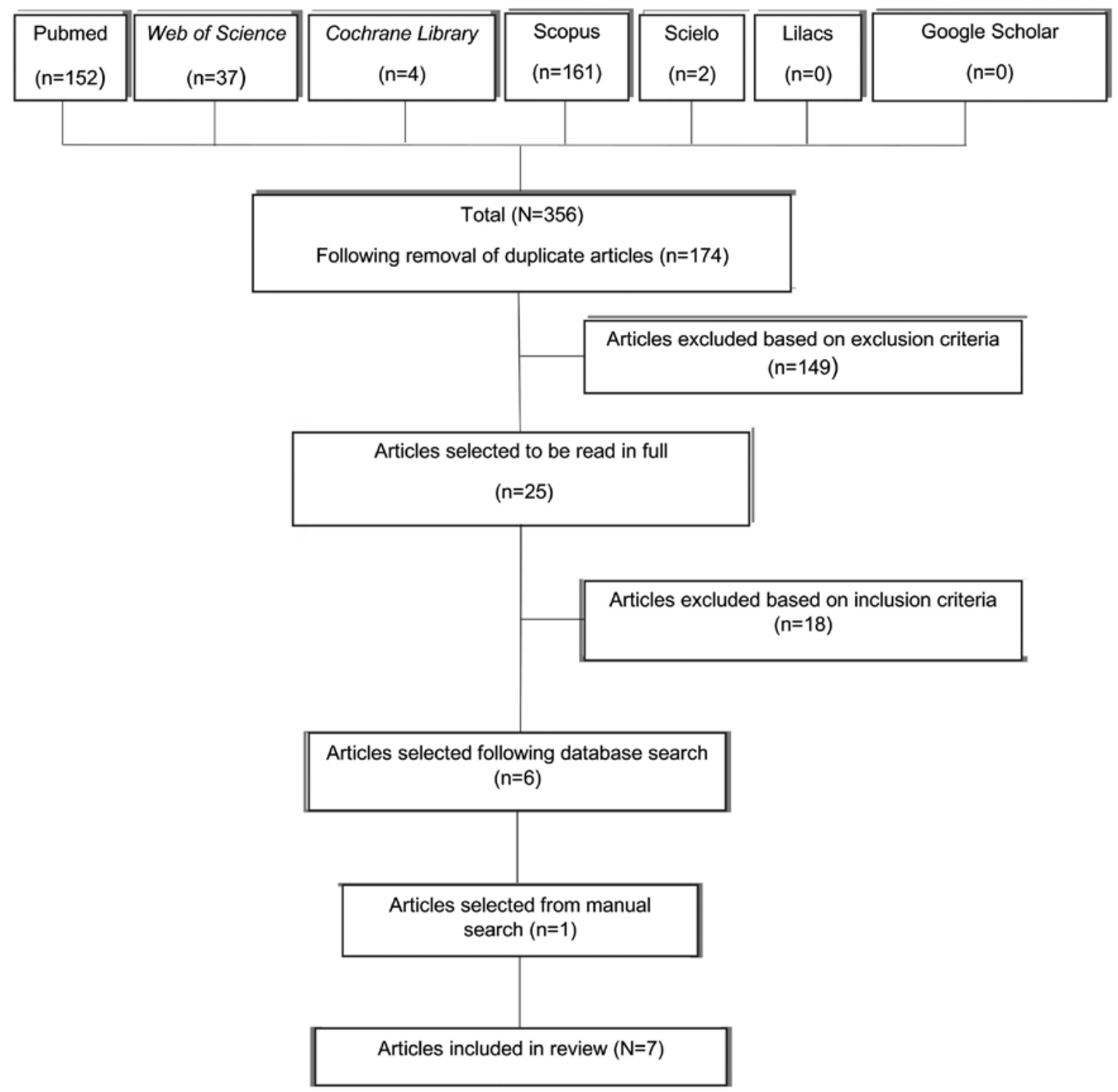

Figure 1. Flowchart of studies analyzed.

A total of 17,003 elderly persons were evaluated, of which 10,098 were women (59.39\%). All the studies included in this review were cross-sectional studies. In these, multimorbidity was found to be associated with smoking, alcohol consumption, living in rural areas, low schooling, the female gender, older elderly persons, the use of health services in the preceding week, family structure (not living with children), polypharmacy and negative selfperception of health (Table 1). Although most studies reported an association between multimorbidity and low economic status, there was a divergence in the results, in this review, when assessing the influence of economic status on the prevalence of multimorbidity. The quality score of the studies ranged from 7 to 8 points.

Mini et al..$^{35}$ in 2017, aimed to calculate the proportion of elderly people with multimorbidity and identify the associated factors, as well as their implications. A total of 9,852 elderly people aged 60 or over were interviewed. As a result, the authors found that in individuals aged $\geq 70$ years, alcohol users, women, tobacco users, and those who were better off were more likely to suffer from multimorbidity. 
Ha et al. ${ }^{36}$, sought to determine the prevalence of multimorbidity in the elderly and to identify associated factors in an elderly population in southern Vietnam. The sample was 2,400 individuals aged 60 years or older. After a multivariate analysis, age, gender, and need for help when performing basic activities of daily living lost statistical significance. On the other hand, being illiterate, living in rural areas and using health services in the previous week were associated with the presence of multimorbidity.

In 2014, Banjare et al. ${ }^{37}$ evaluated the prevalence of the accumulation of chronic conditions among rural elderly persons, as well as associated socioeconomic and demographic factors. A total of 310 elderly individuals were aged 60 years or older. The results obtained from logistic regression analysis showed that older elderly persons, those who were economically dependent and those who smoked were more likely to present multimorbidity. In 2013, Jerliu et al. ${ }^{38}$ evaluated the prevalence of multimorbidity and associated demographic and socioeconomic factors in elderly people in Kosovo. A total of 1,890 individuals aged 65 years and over participated in the study. A total of $45 \%$ of the elderly had at least two chronic diseases. Based on a multivariate analysis, the factors related to the presence of multimorbidity were the female gender, advanced age, self-perceived poverty and difficulty accessing medical care.
Agborsangaya et al. ${ }^{39}$, in 2012, aimed to identify the prevalence of multimorbidity and its sociodemographic factors in adults aged 18 years or older. This study evaluated different age groups, including elderly people aged 65 or over. The sample corresponding to the elderly was 776 individuals. For this population group, multimorbidity was associated with females and those who did not live with children. In 2008, Marengoni et al. ${ }^{40}$ investigated the role of age, gender and socioeconomic status in the occurrence of multimorbidity in the elderly aged from 77 to 100 years. Old age, the female gender and a lower level of schooling were shown to be associated with multimorbidity.

Finally, in 2017, Cavalcanti et al. ${ }^{41}$ sought an association between multimorbidity in the elderly and sociodemographic variables, self-perception of health and polypharmacy. The sample consisted of 676 individuals aged 60 years or older residing in small municipal regions in the north of the state of Rio Grande do Sul, Brazil. Following adjusted analysis, the occurrence of multimorbidity was associated with the variables: negative perception of health and use of polypharmacy. In the crude analysis, multimorbidity was related to the female gender, advanced age, low socioeconomic level and mental disorders. However, when performing the adjusted analysis, these variables lost significance. 


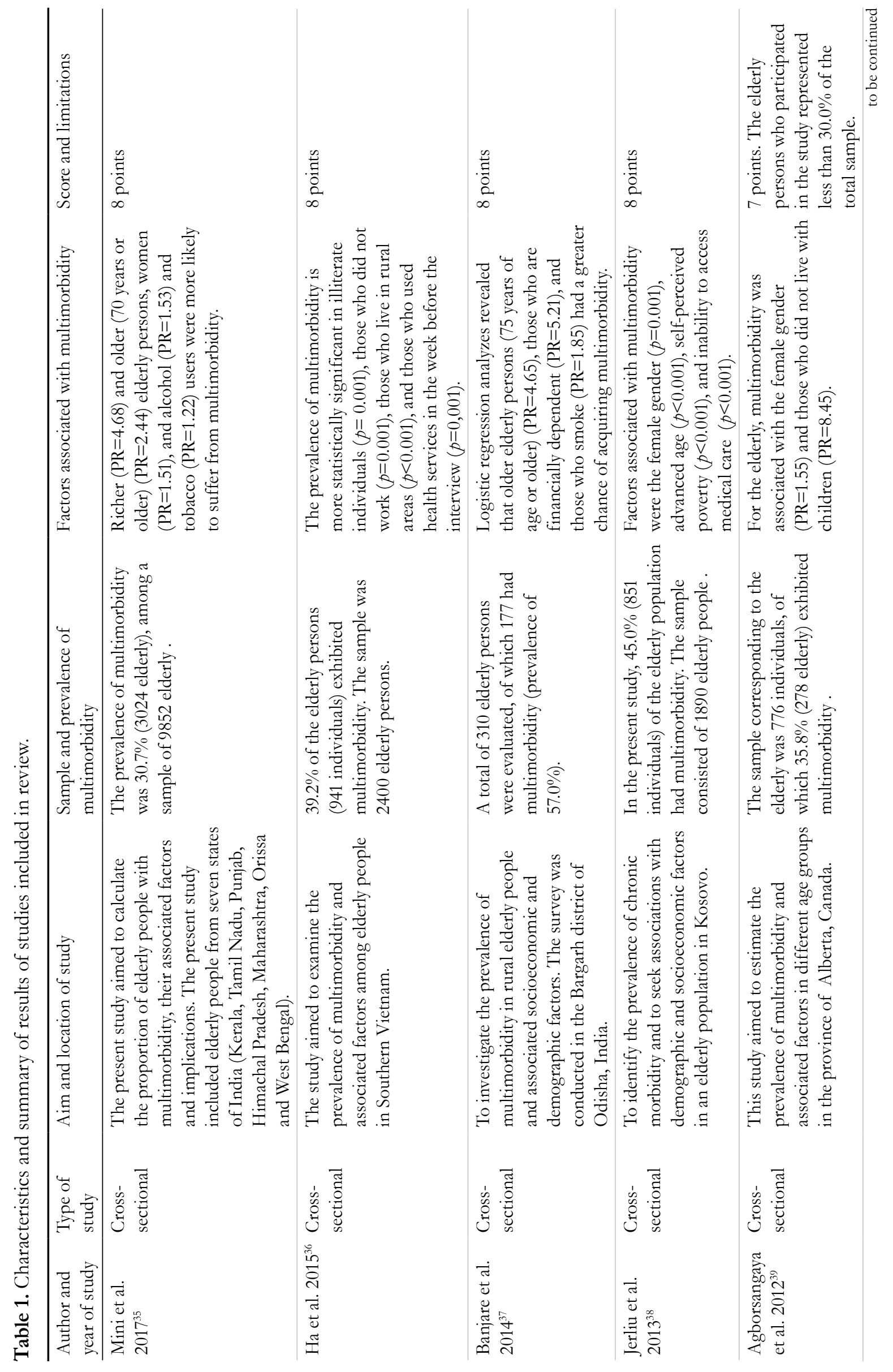




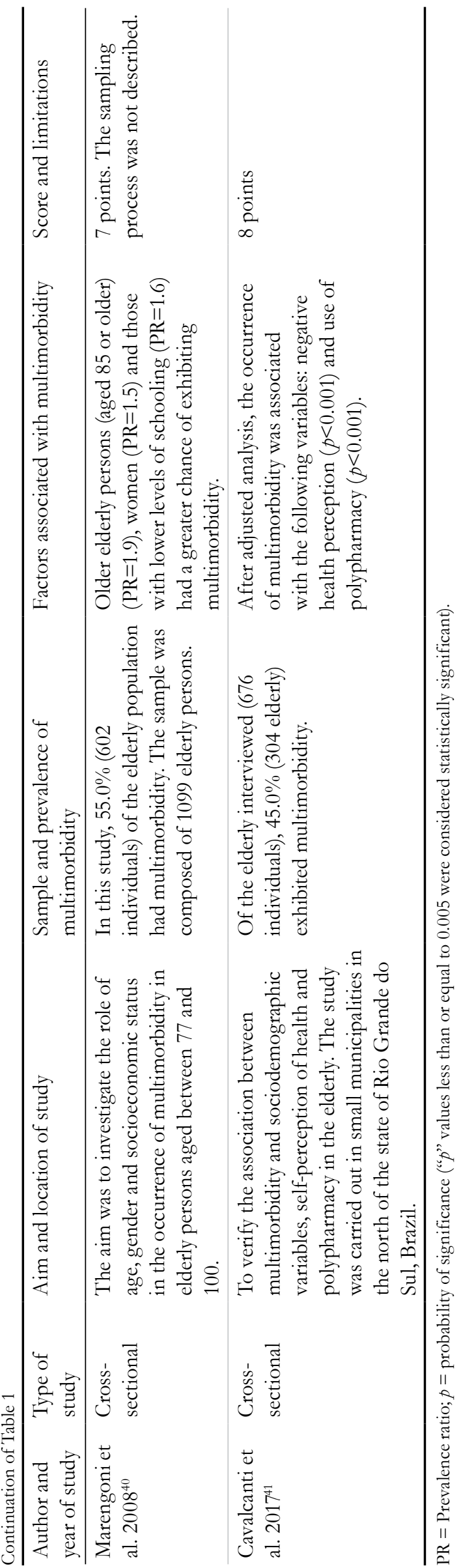




\section{DISCUSSION}

The present study sought to identify, through an integrative literature review, the factors associated with the presence of multimorbidity in the elderly. As a result, all types of studies found that met the established inclusion criteria were included in the review. It was not, however, possible to perform a systematic review of randomized clinical trials, the level of scientific evidence of which is high. The objective of the present study is justified by the absence of elderly persons with multimorbidity in these types of studies, as in most methodological designs, this population group are removed following the application of the exclusion criteria precisely because they suffer from chronic diseases. With regard to the quality of the studies included, the results demonstrated reliability and internal and external validity, with scores ranging from 7 to 8 points, the latter being the maximum score.

From the results of the search strategy a small number of studies which included multimorbidity as the dependent variable were found, which made it difficult to identify more factors that could influence the effects of multimorbidity on the elderly. Furthermore, the age groups of the populations of the studies found varied, reflecting a low level of scientific evidence in responding to the objective of the present study.

In general, the results of the review point to an association between multimorbidity in the elderly and smoking, alcohol consumption, living in rural areas, low schooling, use of health services in the previous week, the female gender, older elderly persons, family structure (not living with children), polypharmacy and a negative self-perception of health. The studies diverged on the influence of economic status on the prevalence of multimorbidity ${ }^{35-41}$.

With regard to lifestyle, only smoking and consuming alcohol were evaluated. Such habits have been found to be associated with multimorbidity, and this correlation can be explained by their interference with the adequate nutrition of the elderly, since alcohol and tobacco compete with nutrients from ingestion to absorption and use $\mathrm{e}^{42}$. In addition, from a public health perspective, alcohol and tobacco are among the five most important risk factors for the emergence of chronic non-communicable diseases ${ }^{42}$.

The strong association between rural living and multimorbidity in the elderly may be due to the poor availability of health services and access to information in these places, which result in fewer opportunities for these elderly people to acquire the healthy habits that prevent the accumulation of chronic diseases ${ }^{43}$. Due to this situation, more efforts should be made to improve health services in these areas, especially for the elderly.

With regard to literacy, the results indicate that people with greater education are less likely to suffer from multimorbidity. Education empowers an individual to seek knowledge. Therefore, educated people may be able to access more information on health promotion and adopt healthy lifestyles, preventing the onset of certain chronic diseases ${ }^{36}$.

The use of health services in the preceding week was positively associated with the prevalence of multimorbidity in the study by $\mathrm{Ha}$ et al. ${ }^{36}$ As the authors established multimorbidity as a dependent variable, the results suggest that the use of health services in the preceding week results in a greater prevalence of multimorbidity. As it is a cross-sectional study, the cause-and-effect relationship of the studied variables cannot be well-established. Therefore, the use of these services seems to be a consequence of the accumulation of chronic diseases, rather than the other way around, since in cases of poorer general health, the elderly seek health services more frequently.

The same occurred with the variables polypharmacy and negative self-perception of health in the study by Cavalcanti et al. ${ }^{41}$ The use of several drugs and the reporting of poor or very poor health seem to be a consequence of the accumulation of chronic diseases, rather than the other way around. The use of polypharmacy can be understood by elderly people's frequent need to take medications for the treatment of chronic diseases, while selfperception of health tends to be negative due to the greater number of hospitalizations of elderly people who suffer from multimorbidity. 
In studies that sought to associate multimorbidity in the elderly with socioeconomic and demographic factors, there was some divergence regarding the associations with gender and family income ${ }^{35-38,41}$. Ha et al. ${ }^{36}$ and Cavalcanti et al. ${ }^{41}$ found no association between multimorbidity and the female gender, whereas Mini et al. ${ }^{35}$, Jerliu et al. ${ }^{38}$, Agborsangaya et al. $^{39}$ and Marengoni et al. ${ }^{40}$ identified such an association. The same thing occurred with economic status. In the study by Mini et al..$^{35}$ an association between multimorbidity and richer elderly persons was observed, whereas Banjari et al. ${ }^{37}$ and Jerliu et al. ${ }^{38}$ observed an association between multimorbidity and self-reported poverty and financial dependence.

The divergence between these studies in relation to such variables may be due to the different age groups of elderly persons analyzed. Mini et al. ${ }^{35}$, Ha et al. ${ }^{36}$, Banjare et al. ${ }^{37}$ and Cavalcanti et al. ${ }^{41}$ considered elderly persons aged 60 years or older, while Jerliu et al. ${ }^{38}$ and Agborsangaya et al. ${ }^{39}$ considered the elderly as being those aged 65 years and over. Marengoni et al. ${ }^{40}$, meanwhile, studied only elderly persons aged from 77 to $110^{35-41}$. The association between the female gender and the prevalence of multimorbidity may be related to the fact that women have a longer life expectancy and worse health status than $\operatorname{men}^{35,38,39}$.

Most of the studies found that older and poorer elderly persons tend to have higher occurrences of multimorbidity $\mathrm{y}^{36,38}$. It is suggested that older elderly persons tend to have more multimorbidities than younger elderly individuals people due to physiological aging ${ }^{38}$. With regard to poorer individuals, economic difficulties continue to be a strong predictor of health, even in the elderly. Poverty appears to be part of a vicious circle: a low income during adulthood favors the persistence of poverty in the aging phase, which in turn contributes to poor health outcomes ${ }^{38}$.

The fact that the high prevalence of multimorbidity is affected by whether the elderly person lives with children or not suggests that living with other people, irrespective of whether it is a spouse, child or grandchild, is extremely important for the health care of the elderly. In addition, the importance of family support through the management of chronic diseases may be an important component in reducing the likelihood of developing other chronic conditions ${ }^{39}$.

The present review found that the prevalence of multimorbidity in the elderly varies from $30.7 \%$ to $57.0 \%$. This broad variation may have occurred due to the study of distinct age groups of elderly persons, as well as the variety of chronic diseases assessed in the different studies. The results showed that multimorbidity is a very common condition in the elderly. Thus, in order to tackle the health care related challenges that aging brings for society, it is necessary to review the organization of health services. Further efforts should be directed at educating health professionals to prioritize primary health care, with a focus on chronic disease prevention. Furthermore, additional health care related to multimorbidity should be dedicated to older, female elderly persons and rural residents.

Finally, considering the small number of studies that include multimorbidity as a dependent variable and that evaluate its associated factors, as well as the divergences regarding the influence of socioeconomic variables, studies with greater population coverage that evaluate the factors associated with multimorbidity in the elderly are required to confirm the results of this review.

\section{CONCLUSION}

In conclusion, the results indicate that multimorbidity in the elderly is a relatively common condition which is influenced by socioeconomic, demographic, lifestyle and family structure factors. The influence of the economic status of the elderly is not yet a consensus in literature. 


\section{REFERENCES}

1. Oliveira MPF, Novaes MRCG. Perfil socioeconômico, epidemiológico e farmacoterapêutico de idosos institucionalizados de Brasília, Brasil. Ciênc Saúde Colet. 2013;18(4):1069-78.

2. Schmidt MI, Duncan BB, Silva GA, Menezes AM, Monteiro CA, Barreto SM. Chronic noncommunicable diseases in Brazil: burden and current challenges. Lancet. 2011;377(9781):1949-61.

3. Salive ME. Multimorbidity in older adults. Epidemiol Rev. 2013;35:75-83.

4. Violan C, Foguet-Boreu Q, Flores-Mateo G, Salisbury C, Blom J, Freitag M. Prevalence, determinants and patterns of multimorbidity in primary care: a systematic review of observational studies. PLos ONE. 2014;9(7):1-9.

5. Nunes BP, Thumé E, Facchini LA. Multimorbidity in older adults: magnitude and challenges for the Brazilian health system. BMC Public Health. 2015;15:1-11.

6. Veras R, Lima-Costa MF. Epidemiologia do envelhecimento. In: Almeida NDF, Barreto ML, editors. Epidemiologia \& saúde: fundamentos, métodos, aplicações. Rio de Janeiro: Guanabara Koogan; 2011. p. 427-37.

7. Murray CJL, Vos T, Lozano R, Naghavi M, Flaxman AD, Michaud C, et al. Disability-adjusted life years (DALYs) for 291 diseases and injuries in 21 regions, 1990-2010: a systematic analysis for the Global Burden of Disease Study 2010. Lancet. 2012;380(9859):2197-2223.

8. Vos T, Flaxman AD, Naghavi M, Lozano R, Michaud C, Ezzati M, et al. Years lived with disability (YLDs) for 1160 sequelae of 289 diseases and injuries 19902010: a systematic analysis for the Global Burden of Disease Study 2010. Lancet. 2012;380(9859):2163-96.

9. Rechel B, Grundy E, Robine JM, Cylus J, Mackenbach JP, Knai C, et al. Ageing in the European Union. Lancet. 2013;381(9874):1312-22.

10. Gijsen R, Hoeymans N, Schellevis FG, Ruwaard D, Satariano WA, Van den Bos GA. Causes and consequences of comorbidity: a review. J Clin Epidemiol. 2001;54(7):661-74.

11. DuGoff EH, Canudas-Romo V, Buttorff C, Leff B, Anderson GF. Multiple chronic conditions and life expectancy: a life table analysis. Med Care. 2014;52(8):688-94.

12. Ording AG, Sorensen HT. Concepts of comorbidities, multiple morbidities, complications, and their clinical epidemiologic analogs. Clin Epidemiol. 2013;5:199-203.
13. Brasil, Ministério da Saúde. Programa de avaliação para a qualificação do Sistema Único de Saúde [Internet]. Brasília, DF: MS; 2011 [acesso em 10 jan. 2018]. Disponível em: http://observasaude.fundap. sp.gov.br/saude2/sus/Acervo/SUS_AvlQualif_3.pdf

14. Kuller L, Tonascia S. A follow-up study of the Commission on Chronic Illness morbidity survey in Baltimore. IV. Factors influencing mortality from stroke and arteriosclerotic heart disease (1954-1967). J Chronic Dis. 1971;24(2):111-24.

15. Loney PL, Chambers LW, Bennett KJ, Roberts JG, Stratford PW. Critical appraisal of the health research literature: prevalence or incidence of a health problem. Chronic Dis Can. 1998;19(4):170-6.

16. Schiøtz ML, Stockmarr A, Høst D, Glümer C, Frølich A. Social disparities in the prevalence of multimorbidity: a register-based population study. BMC Public Health. 2017;17:422.

17. Larsen FB, Pedersen MH, Friss K, Glümer C, Lasgaard M. A Latent class analysis of multimorbidity and the relationship to socio-demographic factors and health-related quality of life. A National PopulationBased Study of 162,283 Danish Adults. PLos ONE. 2017;12(1):1-17.

18. Chung RY, Mercer S, Lai FT, Yip BH, Wong MC, Wong SY. Socioeconomic Determinants of Multimorbidity: a Population-Based Household Survey of Hong Kong Chinese. PLoS One 2015;10(10):1-15.

19. Garin N, Koyanagi A, Chatterji S, Tyrovolas S, Olaya B, Leonardi M, et al. Global Multimorbidity Patterns: a cross-sectional, population-based, multicountry study. J Gerontol Ser A Biol Sci Med Sci. 2016;71(2):205-14.

20. Prazeres F, Santiago L. Prevalence of multimorbidity in the adult population attending primary care in Portugal: a cross-sectional study. BMJ Open 2015;5(9):1-10.

21. Jackson CA, Dobson A, Tooth L, Mishra GD. Body mass index and socioeconomic position are associated with 9-year trajectories of multimorbidity: a population-based study. Prev Med. 2015;81:92-8.

22. Roberts KC, Rao DP, Bennett TL, Loukine L, Jayaraman GC. Prevalence and patterns of chronic disease multimorbidity and associated determinants in Canada. Health Promot Chronic Dis Prev Can. 2015;35(6):87-94.

23. Pavela G, Latham K. Childhood conditions and multimorbidity among older adults. J Gerontol Ser A Biol Sci Med Sci. 2016;71:889-901. 
24. Habib RR, Hojeij S, Elzein K, Chaaban J, Seyfert $\mathrm{K}$. Associations between life conditions and multi-morbidity in marginalized populations: the case of Palestinian refugees. Eur J Public Health. 2014;24:727-33.

25. McLean G, Gunn J, Wyke S, Guthrie B, Watt GCM, Blane DN. The influence of socioeconomic deprivation on multimorbidity at different ages: a cross-sectional study. Br J Gen Pract. 2014;64:440-7.

26. Hermans H, Evenhuis HM. Multimorbidity in older adults with intellectual disabilities. Res Dev Disabil. 2014;35(4):776-83.

27. Phaswana-Mafuya N, Peltzer K, Chirinda W, Musekiwa A, Kose Z, Hoosain E, et al. Self-reported prevalence of chronic non-communicable diseases and associated factors among older adults in South Africa. Glob Health Action 2013;6(1):1-7.

28. Demirchyan A, Khachadourian V, Armenian HK, Petrosyan V. Short and long term determinants of incident multimorbidity in a cohort of 1988 earthquake survivors in Armenia. Int J Equity Health. 2013;12:1-8.

29. Alaba O, Chola L. The social determinants of multimorbidity in South Africa. Int J Equity Health. 2013;12:1-10.

30. Hudon C, Soubhi H, Fortin M. Relationship between multimorbidity and physical activity: secondary analysis from the Quebec health survey. BMC Public Health. 2008;8:1-8.

31. Van den Akker M, Buntinx F, Metsemakers JF, Roos S, Knottnerus JA. Multimorbidity in general practice: prevalence, incidence, and determinants of co-occurring chronic and recurrent diseases. J Clin Epidemiol. 1998;51:367-75.

32. Mwangi J, Kulane A, Van Hoi L. Chronic diseases among the elderly in a rural Vietnam: prevalence, associated socio-demographic factors and healthcare expenditures. Int J Equity Health. 2015;14:1-8.

33. Kuo RN, Lai MS. The influence of socio-economic status and multimorbidity patterns on healthcare costs: a six-year follow-up under a universal healthcare system. Int J Equity Health. 2013;12:1-11.
34. Ruel G, Shi Z, Zhen S, Zuo H, Kröger E, Sirois C, et al. Association between nutrition and the evolution of multimorbidity: the importance of fruits and vegetables and whole grain products. Clin Nutr. 2014;33:513-20.

35. Mini GK, Thankappan KR. Pattern, correlates and implications of non-communicable disease multimorbidity among older adults in selected Indian states: a cross-sectional study. BMJ Open. 2017;7(3):1-6.

36. Ha NT, Le NH, Khanal V, Moorin R. Multimorbidity and its social determinants among older people in southern provinces, Vietnam. Int J Equity Health. 2015;14:1-7.

37. Banjare P, Pradhan J. Socio-economic inequalities in the prevalence of multi-morbidity among the rural elderly in Bargarh District of Odisha (India). PLos ONE. 2014;9(6):1-10.

38. Jerliu N, Toçi E, Burazeri G, Ramadani N, Brand $\mathrm{H}$. Prevalence and socioeconomic correlates of chronic morbidity among elderly people in Kosovo: a population-based survey. BMC Geriatr. 2013:1-9.

39. Agborsangaya CB, Lau D, Lahtinen M, Cooke T, Johnson JA. Multimorbidity prevalence and patterns across socioeconomic determinants: a cross-sectional survey. BMC Public Health. 2012;12:1-8.

40. Marengoni A, Winblad B, Karp A, Fratiglioni L. Prevalence of chronic diseases and multimorbidity among the elderly population in Sweden. Am J Public Health. 2008;98:1198-200.

41. Cavalcanti G, Doring M, Portella MR, Bortoluzzi EC, Mascarelo A, Delani MP. Multimorbidity associated with polypharmacy and negative self-perception of health. Rev Bras Geriatr Gerontol. 2017;20(5):634-42.

42. Zaitune MPA, Barros MBA, César CLG, Carandina L, Goudbaum M. Fatores associados ao sedentarismo no lazer em idosos. Cad Saúde Pública. 2007;23(6):1329-38.

43. Kassouf AL. Acesso aos serviços de saúde nas áreas urbana e rural do Brasil. Rev Econ Sociol Rural 2005;43(1):29-44. 